\title{
A!
}

This is an electronic reprint of the original article.

This reprint may differ from the original in pagination and typographic detail.

Pouresmaeil, Mobina; Sepehr, Amir; Sangrody, Reza; Taheri, Shamsodin; Pouresmaeil, Edris Control of Multilevel Converters for High Penetration of Renewable Energies

Published in:

Proceedings of the 2021 IEEE 12th International Symposium on Power Electronics for Distributed Generation Systems, PEDG 2021

DOI:

10.1109/PEDG51384.2021.9494249

Published: 28/06/2021

Document Version

Peer reviewed version

Please cite the original version:

Pouresmaeil, M., Sepehr, A., Sangrody, R., Taheri, S., \& Pouresmaeil, E. (2021). Control of Multilevel

Converters for High Penetration of Renewable Energies. In S. K. Mazumder, J. C. Balda, L. He, J. Liu, \& A.

Gupta (Eds.), Proceedings of the 2021 IEEE 12th International Symposium on Power Electronics for Distributed

Generation Systems, PEDG 2021 [9494249] (IEEE International Symposium on Power Electronics for

Distributed Generation Systems). IEEE. https://doi.org/10.1109/PEDG51384.2021.9494249

This material is protected by copyright and other intellectual property rights, and duplication or sale of all or part of any of the repository collections is not permitted, except that material may be duplicated by you for your research use or educational purposes in electronic or print form. You must obtain permission for any other use. Electronic or print copies may not be offered, whether for sale or otherwise to anyone who is not an authorised user. 
(C) 2021 IEEE. This is the author's version of an article that has been published by IEEE. Personal use of this material is permitted. Permission from IEEE must be obtained for all other uses, in any current or future media, including reprinting/republishing this material for advertising or promotional purposes, creating new collective works, for resale or redistribution to servers or lists, or reuse of any copyrighted component of this work in other works. 


\section{Control of Multilevel Converters for High Penetration of Renewable Energies}

\author{
Mobina Pouresmaeil, Amir Sepehr \\ Dept. of Elec. Eng. and Automation \\ Aalto University \\ Espoo, Finland \\ Mobina.pouresmaeil@aalto.fi \\ Amir.sepehr@aalto.fi
}

\author{
Reza Sangrody \\ Dept. of Elec. and Computer \\ Eng. \\ Islamic Azad University \\ Firoozkooh, Iran \\ Reza.sangrody@gmail.com \\ Edris Pouresmaeil \\ Dept. of Elec. Eng. and Automation \\ Aalto University \\ Espoo, Finland \\ edris.pouresmaeil@aalto.fi
}

\author{
Shamsodin Taheri \\ Dept. of Eng. and Computer \\ science, \\ Université du Québec en \\ Outaouais (UQO), \\ Gatineau, Canada \\ shamsodin.taheri@uqo.ca
}

\begin{abstract}
Increasing integration of converter-interfaced renewable power generation challenges the stability of the frequency in the modern power systems due to the lack of inertia in this type of generators. In this regard, this paper establishes a control method for controlling multilevel converters as an interface between renewable power generation and the power grid, which enables them to operate as voltage-controlled sources, thus grid-forming capabilities like conventional synchronous generators (SGs). In fact, the proposed control technique mimics the behavior of synchronous generators in the control loop of the neutral point clamped (NPC) converter. Consequently, supportive functionalities for frequency stability i.e., inertia and frequency/power oscillation damping will be provided by the multilevel converter as a virtual synchronous generator (VSG). Simulation results in Matlab/Simulink verifies the well-designed inertia and damping features for the interfaced converter as well as appropriate performance of multilevel converter in reducing total harmonic distortion (THD).
\end{abstract}

Keywords-inertia emulation, neutral point clamped (NPC) converter, oscillation damping, renewable energy sources (RESs), total harmonic distortion (THD).

\section{INTRODUCTION}

The stable operation of the power grids is mainly provided through the operation of synchronous generators (SG) in centralized and dispatchable power plants. SGs have inertia due to their rotational masses and can show frequencyoscillation damping because of rotor damper winding and rotational friction. In addition, SGs can operate in grid-forming operating mode and provide huge amount of short-circuit currents by external excitation during fault events.

The growing integration of converter-interfaced (less inertia) renewable energy sources (RESs) will sooner or later substitute dispatchable SGs, leading to increased energy fluctuations. Consequently, these changes cause larger frequency deviations and voltage regulation problems in future power grids [1], [2]. This is because these generators have neither rotor inertia nor SGs damping property. The lack of inertia and damping characteristic of such generators can be solved by modifying the control scheme of converter-based units and providing new ancillary services for power grids through the converter-based generators [3]. Depends on whether all dynamics of SGs are emulated in the control loop of the converter or just some of the most important features of SGs are considered, these techniques are divided into highorder and low-order virtual synchronous generator (VSG) techniques.

The VSG techniques based on swing equation (low- order) include the most important characteristics of SGs, i.e. inertia and oscillation damping property, while high-order techniques incorporate detailed equations and as a result are more difficult to implement. The VSG techniques based on swing equation are the focus of the current researches [4], [5]. An extensive comparison between a swing-based and a fully detailed VSG control schemes has been presented in [6], which declares that the low-order VSG techniques are more stable in comparison with the high-order techniques.

A low-order topology based on frequency-power response is presented in [7] in which the swing equation is used to control the output power of the converter. The idea of distributed virtual inertia in grid-connected converters is presented in [8], in which the stored energy in the dc-link capacitor is employed to provide virtual inertia and support frequency at the point of common coupling (PCC). However, in this method, some parameters of the converter may limit the provided virtual inertia. Generally, techniques for the gridfollowing converters in which the power setpoint for current or 
power controller is a function of the measured frequency by phase locked loop (PLL), operation of converters in weak grids is quite challenging, because strength of power grid affects the operation of such converters, and control can become unstable when it is expected to provide more inertia [1], [3]. As a result, relying on grid-following converters is not appropriate for a fully converter-based system and many researches focus on inertia emulation on grid-forming converters [9]-[11]. An open loop control scheme is proposed in [9] for control of the gridforming converter, in which the inertia is emulated through swing equation, and the reference voltage amplitude is defined directly by reactive power controller. Such open loop structures are not able to provide overcurrent protection and some other supportive functionalities. To address this issue, a virtual synchronous machine control scheme is proposed in [10], wherein a cascaded voltage and current controller is employed to provide switching signals for the interfaced converter. Small signal analysis and parameter sensitivity of this concept in islanded mode of operation is presented in [11] to demonstrate the ability of this concept to operate both in grid-connected and islanded modes.

In this paper, a control technique is proposed to control the grid-forming converters in which inertia, oscillation damping, and frequency regulation are important features emulated to ensure frequency stability of power systems under large share of renewable energies. Moreover, a multilevel converter is employed as an interfacing system between RESs and the power grid. Although conventional 2-level converters are normally used for integration of RESs, multilevel converters have many advantages. The voltage on each switching device is less than the output voltage, so there is no need to be worried about voltage rating of switching devices and it offers a connection of converter to the grid without transformer for increasing the output voltage of converter. Moreover, multilevel converters can provide high-quality power with low total harmonic distortion (THD) [12]. Considering advantages of multilevel converters, a 3-level diode-clamped converter is used in this study as an interface between renewable energy sources and the power grid. The active power-frequency (P-f) droop curve equation and the swing equation including inertia and damping property of SGs are applied to extract the mechanical speed and mechanical phase angle for the inner voltage control and current control loops in the dq reference frame.

The rest of this paper is prepared as follows. Section II presents the used model for analysis and the overall control structure. Simulation results will be discussed in Section III to confirm the performance of the proposed control method in control of multilevel converters, and finally Section IV concludes this study.

\section{GENERAL MODEL AND CONTROL DESCRIPTION}

The used model for the analysis and the structure of the proposed control method will be described in detail in this section. The general model and its control scheme are depicted in Fig. 1. As shown in this figure, an NPC converter is used as an interface between the renewable energy sources and the power grid. To facilitate analysis of the proposed model, the general model of renewable energy sources is shown through a DC sources. Conventional current and voltage component terms are also indicated in this model. An LC filter with inductance $L_{f}$ and capacitor $C_{f}$ is used to filter out the output power of the interfaced NPC converter.

The structure of the proposed control method includes internal voltage and current control loops, and external powerfrequency control loop. The inner control loop results in 12 switching signals to switch the insulated-gate bipolar transistors (IGBTs) embedded in the interfaced multilevel converter. Implementation of the vector current and voltage controllers are based on the electric model equations expressed as follows [13]:

$$
\begin{gathered}
L_{f} \frac{d i_{m l, a b c}}{d t}+R_{f} i_{m l, a b c}+v_{a b c}=u_{a b c} \\
C_{f} \frac{d v_{a b c}}{d t}=i_{m l, a b c}-i_{a b c}
\end{gathered}
$$

where, $v_{a b c}$ and $i_{a b c}$ represent the voltage and current at PCC, and $u_{a b c}$ and $i_{m l, a b c}$ are voltage and current at multilevel converter terminal, respectively.

Using the well-known park transformation, the AC-side dynamics of the interfaced converter, described by (1) and (2), can be transferred to dq reference frame as:

$$
\begin{gathered}
L_{f} \frac{d i_{m l, d}}{d t}+R_{f} i_{m l, d}-L_{f} \omega i_{m l, q}+v_{d}=u_{d} \\
L_{f} \frac{d i_{m l, q}}{d t}+R_{f} i_{m l, q}+L_{f} \omega i_{m l, d}+v_{q}=u_{q} \\
C_{f} \frac{d v_{d}}{d t}+i_{d}-C_{f} \omega v_{q}=i_{m l, d} \\
C_{f} \frac{d v_{q}}{d t}+i_{q}+C_{f} \omega v_{d}=i_{m l, q}
\end{gathered}
$$

where, the term $\omega$ is the angular frequency provided by the outer power-frequency control loop.

As depicted in Fig. 1, proportional-integral (PI) controllers are used in the current control loop to track accurately the reference current components $\left(i_{m l, d}^{*}, i_{m l, q}^{*}\right)$ defined by the voltage controller. Therefore, the switching state functions associated with the current controller defined in dq reference frame is given by:

$$
\begin{aligned}
& u_{d}=v_{d}-L_{f} \omega i_{m l, q}+\left(K_{p i}+\frac{K_{i i}}{s}\right)\left(i_{m l, d}^{*}-i_{m l, d}\right) \\
& u_{q}=v_{q}+L_{f} \omega i_{m l, d}+\left(K_{p i}+\frac{K_{i i}}{s}\right)\left(i_{m l, q}^{*}-i_{m l, q}\right)
\end{aligned}
$$




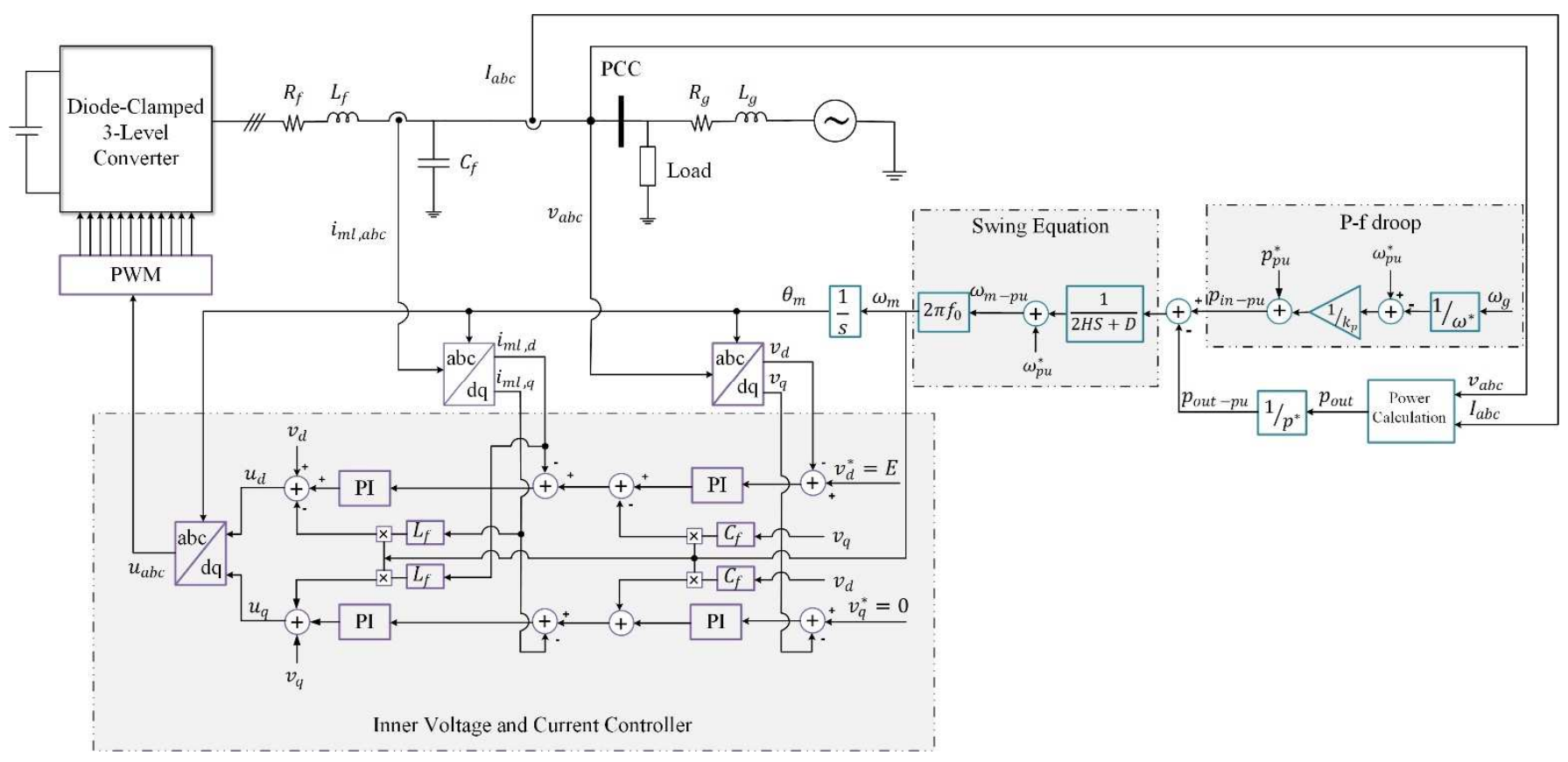

Fig. 1. General model and corresponding control method.

The PI controllers are also employed for the voltage control loop which can be extracted from (9) and (10). By setting the q-axis of reference voltage into the zero value, the value of the d-axis of reference voltage will be equal to the amplitude of the maximum phase voltage of the grid. However, in case the voltage control regulation is needed or in applications with parallel operation of two or more grid-supporting units, reactive power-voltage $(\mathrm{Q}-\mathrm{V})$ droop should be employed to generate the d-axis reference voltage.

$i_{m l, d}^{*}=\left(K_{p v}+\frac{K_{i v}}{s}\right)\left(v_{d}^{*}-v_{d}\right)-C_{f} \omega v_{q}$

$i_{m l, q}^{*}=\left(K_{p v}+\frac{K_{i v}}{s}\right)\left(v_{q}^{*}-v_{q}\right)+C_{f} \omega v_{d}$

To add the characteristics of SGs into the control scheme of the interfaced converter, an outer control loop will be responsible for creating mechanical angular frequency $\left(\omega_{m}\right)$ and mechanical phase angle $\left(\theta_{m}\right)$. In the outer control loop, the well-known swing equation is utilized to represent the inertia and damping property of SG. The swing equation is expressed in per unit system as:

$2 H \frac{d \omega_{m}}{d t}=P_{i n_{p u}}-P_{o u t_{p u}}-D\left(\omega_{m}-\omega_{g}\right), \frac{d \theta_{m}}{d t}=\omega_{m}$

where, the terms $P_{i n \_p u}$ and $P_{\text {Out } \_p u}$ denote the input and the output active power of the interfaced converter, D represents the damping factor, $\mathrm{H}$ represents the inertia constant, $\omega_{m}$ represents the mechanical angular frequency, and $\omega_{g}$ represents the angular frequency at PCC measured by PLL. It should be taken to account that PLL is just employed to provide the system frequency to implement the swing equation.

The P-f droop control is employed in the outer control loop of the converter to represent the role of governor in SG for regulating the frequency. This relationship between frequency and power is shown in (12), makes the frequency adjustable and manages the order of the various RESs participation in the primary frequency response. The active power injection will be a linear function of the frequency, emulating the behavior of conventional SGs used as reserves.

$$
P=P^{*}+K_{p f}\left(\omega^{*}-\omega_{g}\right)
$$

Adding this outer control loop for extracting $\omega_{m}$ and $\theta_{m}$ leads to a grid supporting unit with the capability of working in parallel with other grid-forming units, making the fully converter-based system with enough inertia and frequency stability possible. Therefore, the interfaced converters will be able to operate similarly, and exhibit or even enhance all of the SG functionalities, which are crucial for the stability of the voltage and frequency of the power grid. However, contrary to the conventional SGs, these supportive functionalities provided by the interfaced converters will be continuously controllable, adaptable, and independent of the RESs operating conditions.

It should be also mentioned that the proposed control method can be employed in both grid-connected and standalone operating modes of power converters and has the capability to transfer from the grid-connected mode into the stand-alone mode without changing its control structure. In this study, the unit is employed just in grid-connected operating mode. 


\section{RESUlTS AND DISCUSSION}

In order to evaluate the performance of the proposed control technique in control of converter-interfaced renewable energy sources, the presented model in Fig. 1 is simulated by means of the "Simscape" simulator running in the Matlab/Simulink environment. Parameters of the model under study and the associated control method are summarized in Table I. Different scenarios have been considered in the simulations and the results have been presented and discussed to provide validity of the capability of the proposed control technique to guarantee frequency stability of the future converter-based power grid. As virtual inertia and oscillation damping are two important features emulated in the proposed model, the impact of inertia constant and damping factor on the system dynamics is shown at first. Then, the impact of employing multilevel converter on improving the power quality is shown by comparing THD in the output voltage/ current of the used model and those of 2-level converter ones.

First, the model operates normally with a $40 \mathrm{~kW}+\mathrm{j} 2 \mathrm{kVar}$ load. The converter is intended to supply the whole $40 \mathrm{~kW}$ active power of the load as the reference for its input active power is also considered $40 \mathrm{~kW}$. Then, there is an increment of $4 \mathrm{~kW}$ load at $\mathrm{t}=3 \mathrm{sec}$. Fig. 2 shows the injected active power from the converter to supply the load before and after of the load increment with different amounts of the inertia constants (i.e., $\mathrm{H}=1 \mathrm{Sec}$ and $\mathrm{H}=3 \mathrm{Sec}$ ). As can be seen, at the time of frequency disturbance caused by $10 \%$ step-change in active load, the converter-based unit is able to provide more active power for a short time after disturbance which looks like the released power from the SGs in frequency disturbances. The ability of the converter increases with the increase of inertia constant.

TABLE I. PARAMETERS OF THE PROPOSED MODEL AND ASSOCIATED CONTROL METHOD

\begin{tabular}{|c|c|c|}
\hline Parameter & Description & Value \\
\hline$v$ & Nominal voltage & $380 \mathrm{~V}$ \\
\hline$P_{0}$ & Rated power & $40 \mathrm{~kW}$ \\
\hline$f$ & Nominal frequency & $50 \mathrm{~Hz}$ \\
\hline$f_{s w}$ & Switching frequency & $5 \mathrm{kHz}$ \\
\hline$H$ & Inertia constant & $3 \mathrm{~s}$ \\
\hline$D$ & Damping factor & 100 \\
\hline$k_{p}$ & P-f droop coefficient & 0.05 \\
\hline$L_{f}$ & Filter inductance & $2 \mathrm{mH}$ \\
\hline$C_{f}$ & Filter capacitor & $10 \mu \mathrm{F}$ \\
\hline$R_{g}, L_{g}$ & Grid impedance & $0.12 \Omega, 4 \mathrm{mH}$ \\
\hline
\end{tabular}

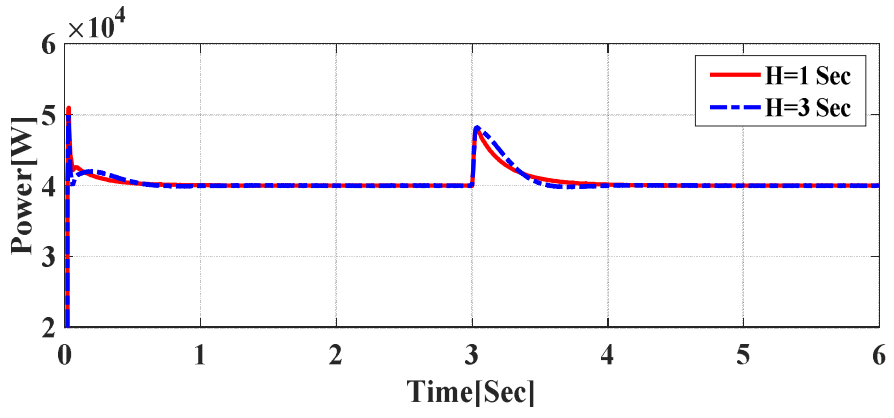

Fig. 2. Output active power of the interfaced converter comparing different amounts of the inertia constants.

Fig. 3 illustrates the frequency at the PCC before and after $10 \%$ load increment with different amounts of the inertia constants. As can be seen, rising inertia constant from $\mathrm{H}=1 \mathrm{sec}$ to $\mathrm{H}=3 \mathrm{sec}$ results in $33 \%$ decrease in frequency nadir, i.e. the maximum deviation from nominal frequency, which means the frequency stability is enhanced appropriately through proper operation of the proposed control method for control of interfaced converter.

The output active power and frequency of the interfaced converter under the same scenarios are shown in Fig. 4 and Fig. 5 comparing two amounts of damping factors (i.e., $\mathrm{D}_{0}$ and $\mathrm{D}_{0} / 2$ ). As clearly can be seen from these figures, increasing amount of the damping factor reduces the oscillation of frequency and power.

Finally, power quality of the proposed model is evaluated by comparing it with the model with 2-level converter instead of 3-level diode-clamped converter. The value of THD of voltage and current are depicted in Fig. 6 and Fig. 7 respectively, comparing the 3-level converter with the conventional 2-level converter. As shown in these figures, with 3-level diode-clamped converter, THD has been reduced comparatively from $3 \%$ to $1 \%$ which confirms the power quality improvement in performance of the proposed control method.

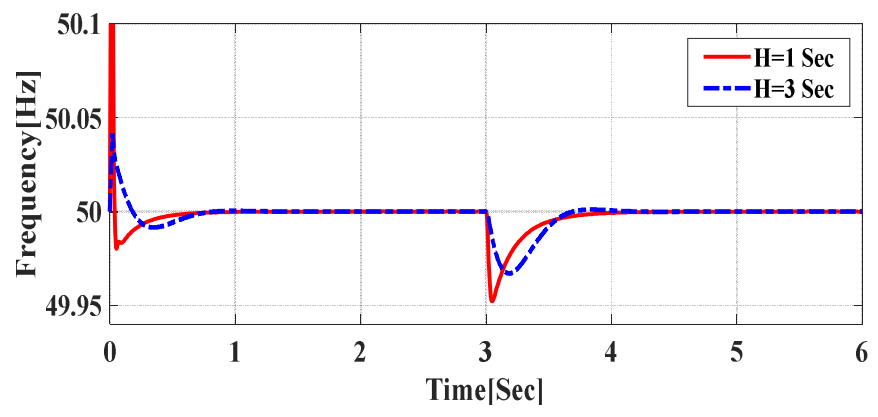

Fig. 3. Frequency at PCC comparing different amounts of the inertia constants. 


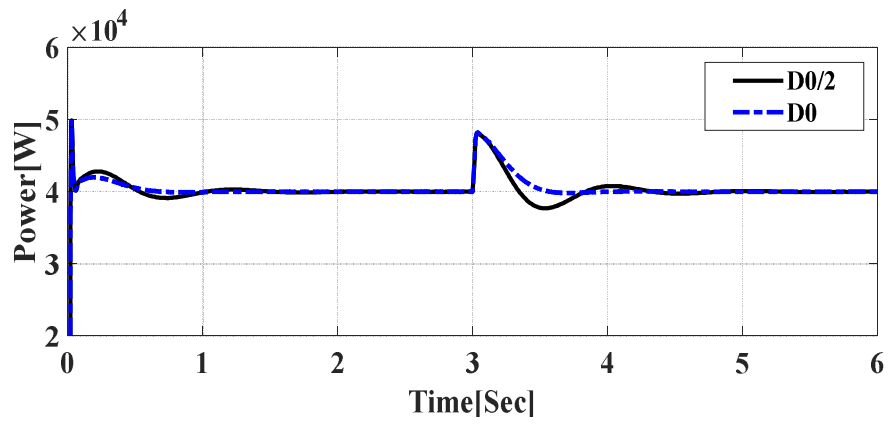

Fig. 4. Output active power of the interfaced converter comparing different amounts of damping factors.

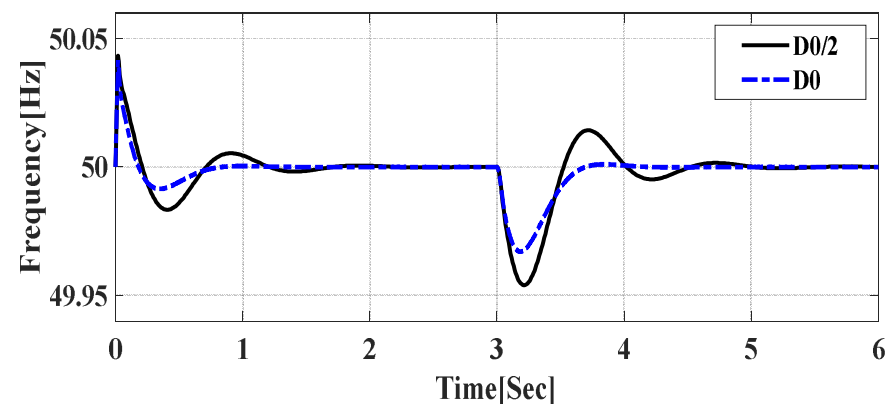

Fig. 5. Frequency at the PCC comparing different amounts of damping factors.

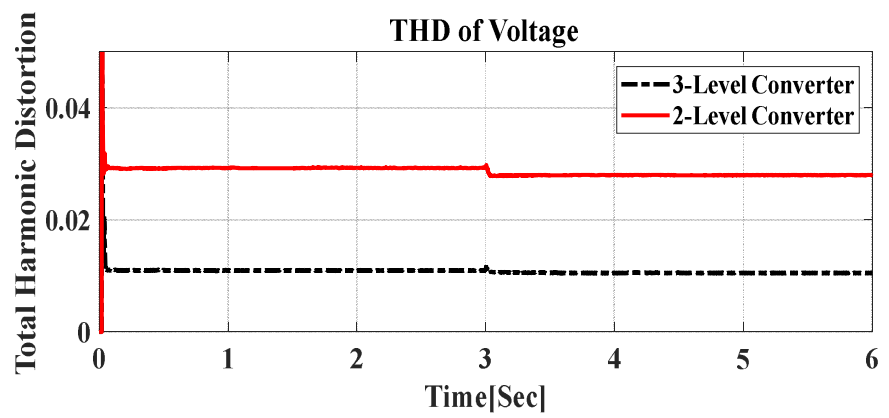

Fig. 6. THD of voltage comparing two-level and three-level converters performance.

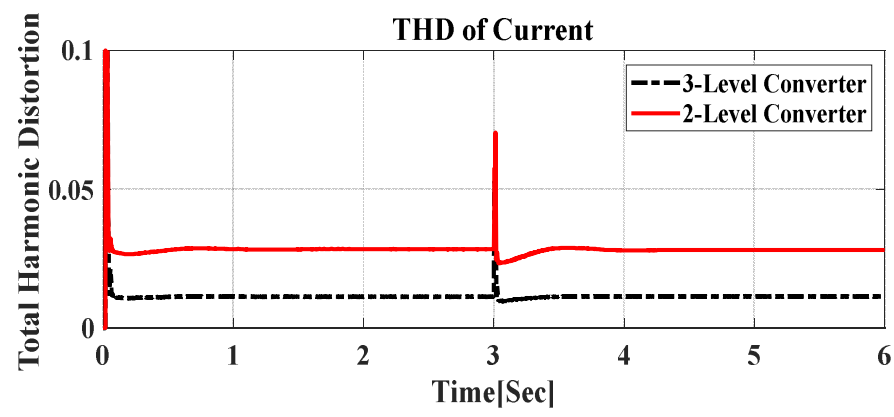

Fig. 7. THD of current comparing two-level and three-level converters performance.

\section{CONCLUSION}

In this paper, a control method has been proposed for control of multilevel converter to ensure frequency stability of the future converter-based power grid. By employing the proposed control technique, interfaced converter mimics the behavior of the conventional synchronous generators to provide required supportive functionalities during transient and steady state operating conditions. These methodologies will make sure that various technical constraints within the power grids are met, and will enable significant displacement of traditional dispatchable SGs, while preserving or even enhancing the current grid stability, even at $100 \%$ RES penetration.

Simulation results also confirms that by multilevel converter high quality power are provided for the power grid through integration of renewable energy sources.

\section{REFERENCES}

[1] C. Collados-Rodriguez, M. Cheah-Mane, E. Prieto-Araujo, andO. GomisBellmunt, "Stability analysis of systems with high vsc penetration: Where is the limit?" IEEE Transactions on Power Delivery, vol. 35, no. 4, pp. 2021-2031, Aug. 2020.

[2] J. Liu, Y. Miura, and T. Ise, "Comparison of dynamic characteristics between virtual synchronous generator and droop control in inverterbased distributed generators, "IEEE Transactions on Power Electronics, vol. 31, no. 5, pp. 3600-3611, May 2016.

[3] P. Tielens, "'Operation and control of power systems with low synchronous inertia," Ph.D. dissertation, Dept. Elect. Eng., Katholieke Univ. Leuven, Leuven, Belgium, Nov. 2017.

[4] Q. C. Zhong and G. Weiss, "Synchronverters: Inverters that mimic synchronous generators," IEEE transactions on industrial electronics, vol. 58, no. 4, pp. 1259-1267, April 2011.

[5] K. Sakimoto, Y. Miura, and T. Ise, "Stabilization of a power system with a distributed generator by a virtual synchronous generator function," in Proceedings of the 8th International Conference on Power ElectronicsECCE Asia, 2011, Jeju, Korea, pp. 1498-1505, 30 May- 3 June 2011.

[6] H. A. Alsiraji and R. El-Shatshat, "Comprehensive assessment of virtual synchronous machine based voltage source converter controllers," IET Generation, Transmission \& Distribution, vol. 11, no. 7, pp. 1762-1769, May 2017.

[7] M. Van Wesenbeeck, S. De Haan, P. Varela, and K. Visscher, "Grid tied converter with virtual kinetic storage," in PowerTech, 2009 IEEE Bucharest, July 2009.

[8] J. Fang, H. Li, Y. Tang, and F. Blaabjerg, "Distributed power system virtual inertia implemented by grid-connected power converters," IEEE Transactions on Power Electronics, vol. 33, no. 10, pp. 8488-8499, October 2018.

[9] J. Alipoor, Y. Miura, and T. Ise, "Power System Stabilization Using Virtual Synchronous Generator with Alternating Moment of Inertia," IEEE journal of Emerging and selected power, vol. 3, no. 2, pp. 451458, Jun. 2015.

[10] S. D'Arco, J. A. Suul, and O. B. Fosso, "Small-Signal Modelling and Parametric Sensitivity of a Virtual Synchronous Machine," in Proc. of the 18th Power Systems Computation Conf., PSCC 2014, Wrocław, Poland, 18-22 August 2014, 9 pp.

[11] S. D'Arco, J. A. Suul, and O. B. Fosso, "Small-signal modeling and parametric sensitivity of a virtual synchronous machine in islanded operation," International Journal of Electrical Power \& Energy Systems, vol. 72, pp. 3-15, November 2015.

[12] E. Pouresmaeil, M. Mehrasa, and J. P. S. Catalão, "Control strategy for the stable operation of multilevel converter topologies in DG technology," in Proc. of the 18th Power Systems Computation Conf., PSCC 2014, Wrocław, Poland, 18-22 August 2014, 7 pp.

[13] J. Rocabert, A. Luna, F. Blaabjerg, and P. Rodriguez, "Control of Power Converters in AC Microgrids," IEEE Transactions on Power Electronics, vol. 27, no. 11, pp. 4734-4739, November 2012. 